\section{The effects of unpaired US presentations on conditioning of the rabbit's nictitating} membrane response: Consolidation or contingency*

\author{
PRISCILLA GREVERT and JOHN W. MOORE \\ University of Massachusetts, Amherst, Mass. 01002
}

Thirty-two rabbits were run in an experiment that showed interference of nictitating membrane conditioning with presentation of one US alone between each paired trial. This conclusion is based on comparisons with yoked control Ss with the same number of paired trials, but no US-alone trials. Differences between experimental and control Ss were most pronounced at a comparatively short ITI, supporting Papsdorf's consolidation theory over Rescorla's contingency hypothesis. This study also elaborated previous results indicating that, prior to the appearance of the first CR, the UR on US-alone trials progressively decreases in amplitude in relation to UR amplitude on paired trials.
A recent experiment (Hupka, Kwaterski, \& Moore, 1970) reported that unpaired impaired conditioning of the nictitating membrane response (NMR) in rabbits. It was also reported that the unconditioned NMR gradually decreased in amplitude on US-alone (USa) trials but not on paired trials. This result is in direct contrast to the conditioned diminution of the UR observed with the human eyeblink (Kimble \& Ost, 1961).

One explanation for the detrimental effect of USa presentations on conditioning concerns the disruptive influences of the interpolated USa trials on the processes that underlie the formation of the association between the CS and US. Such a disruption-of-consolidation interpretation has been favored by Papsdorf and his associates (Kettlewell \& Papsdorf, 1967; Papsdorf \& Kettlewell, 1968; Snyder \& Papsdorf, 1965) who have reported similar disruptive effects on rabbit NMR conditioning caused by the interpolation of changes of illumination or bursts of white noise occurring within the ITI. Ost (1969) has recently emphasized that the consolidation hypothesis based on the proactive and retroactive influences of the interpolated stimulus (IS) on conditioning. Ost points out that there is little empirical justification at this time for favoring one interpretation over the other. For the purposes of this study, the consolidation hypothesis was taken to mean that the intertrial stimulus influences performance by either proactively or retroactively disrupting the formation of the CR.

*This research was supported by NSF Grant GB-8634. Requests for reprints should be addressed to J. W. Moore, Department of Psychology, University of Massachusetts, Amherst, Mass. 01002. presentations of the US during the ITI the Papsdorf research incorporates both
An alternative to Papsdorf's consolidation notion is Rescorla's hypothesis (e.g., 1968) that conditioning is directly related to the uniqueness of the contingency between the CS and US. According to this hypothesis, when the US is presented alone its presence is contingent on stimuli other than the CS and conditioning to the $\mathrm{CS}$ is diminished. If unpaired US presentations during the ITI disrupt a consolidation process, the deleterious effect should be most pronounced as ITI duration decreases. Given enough time, the CS-US connection "hardens" and becomes invulnerable to disruption. However, if the contingency between the CS and US is reduced by the unpaired US presentations, it seems unlikely that the length of the ITI would have any differential effect upon disruption of conditioning.

In the present experiment $S s$ in the experimental group received unpaired US presentations within either a short or a comparatively long ITI, while control Ss received the same number of conditioning trials, but no US-alone trials. Papsdorf's consolidation hypothesis would predict a greater decrement in conditioning in the experimental group with the shorter ITI. Rescorla's contingency notion would predict inferior conditioning at both ITIs. SUBJECTS

The Ss were 32 naive male and female New Zealand White rabbits, 90-120 days old.

\section{APPARATUS}

A detailed description of the apparatus and technique for recording from the nictitating membrane is available elsewhere (Gormezano, 1966). Briefly, two experimental and two control Ss were run concurrently (yoked) and assigned randomly to four ventilated illuminated fireproofed file drawers. Each $\mathrm{S}$ was restrained within Plexiglas boxes identical to those described by Gormezano. The CS was a $1,000-\mathrm{Hz}$ tone ( $70 \mathrm{~dB}$ SPL). The CS

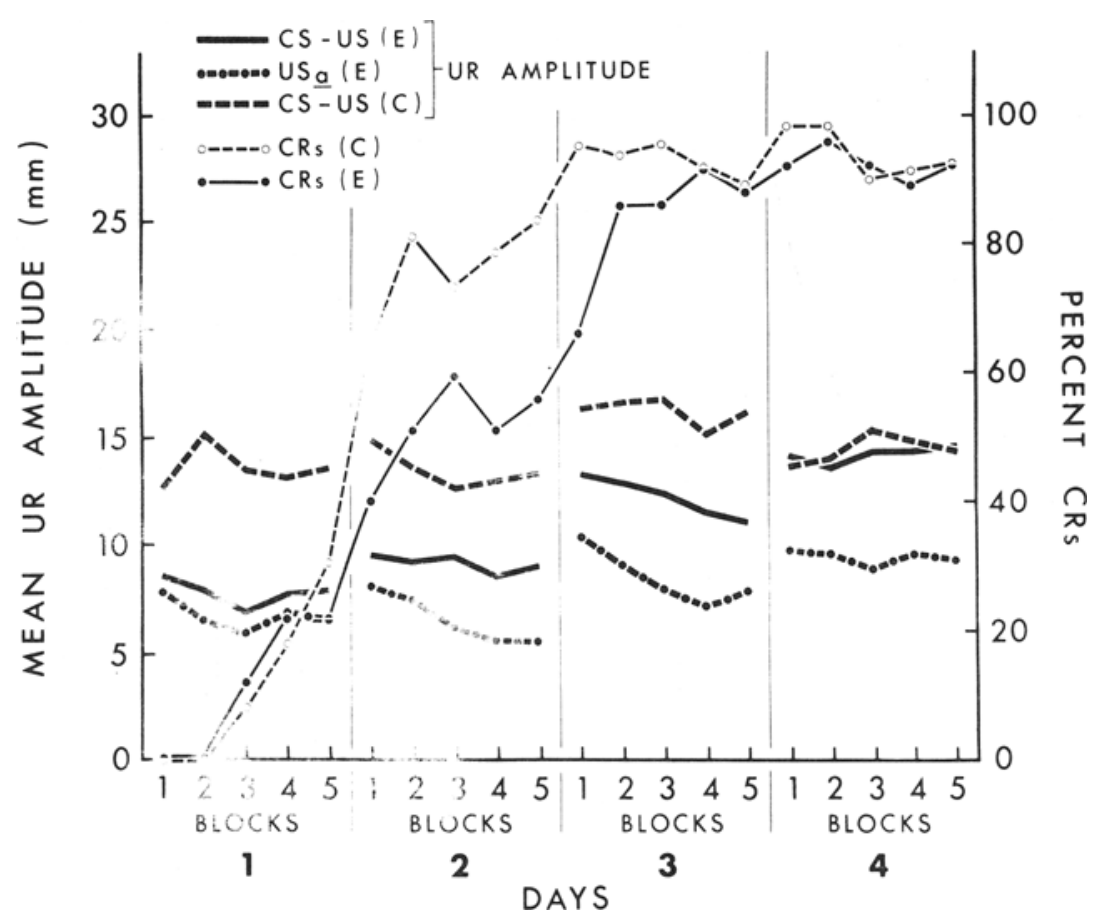

Fig. 1. Mean percentage of CRs and UR amplitude in millimeters for experimental (E) and control (C) Ss at a 100-sec ITI as a function of five daily blocks of 10 CS-US trials for 4 days of acquisition. 


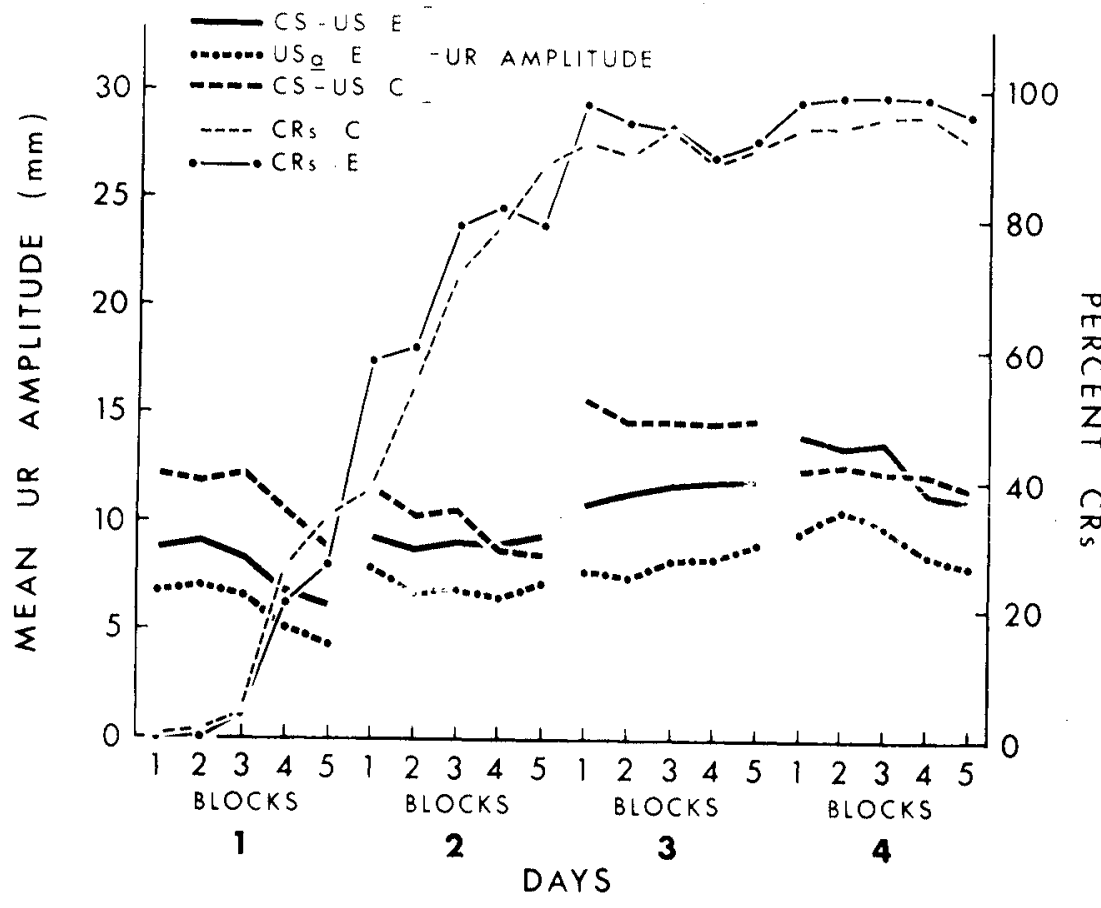

Fig. 2. Mean percentage of CRs and UR amplitude in millimeters for experimental (E) and control (C) Ss at a 200-sec ITI as a function of five daily blocks of $10 \mathrm{CS}$-US trials for 4 days of acquisition.

occurred $250 \mathrm{msec}$ prior to the US, a $2-\mathrm{mA}$ infraorbital shock of $50 \mathrm{msec}$ duration delivered via wound clips.

\section{PROCEDURE AND DESIGN}

Rabbits were assigned randomly to the cells of a 2 by 2 factorial design combining experimental and control conditions with ITIs of 100 and $200 \mathrm{sec}$. Eight experimental Ss received 50 daily CS-US trials at a constant ITI of $200 \mathrm{sec}$. Both experimental groups received 50 interpolated USa trials per session, one occurring within each ITI and varying around the midpoint of the ITI. For the 100 -sec group the interval between CS.US and USa trials averaged $50 \mathrm{sec}$ and ranged from 40 to $60 \mathrm{sec}$; for the 200 -sec group the CS-US to USa interval averaged $100 \mathrm{sec}$ and ranged from 90 to $110 \mathrm{sec}$. Sixteen control Ss received 50 CS-US trials, eight at the 100-sec ITI and the other eight at the $200-\mathrm{sec}$ ITI, but no USa trials. Two experimental and two control Ss were run simultaneously, with both experimental and control $S$ s receiving the same pattern of CS.US trials. Four days of acquisition training were immediately followed by 2 days of extinction. The nictitating membrane was sutured on the day before the first conditioning session and $\mathrm{Ss}$ were habituated to the apparatus by being placed in the restraining box and kept in the experimental enclosure for $30 \mathrm{~min}$.

RESPONSE MEASUREMENT

A CR was defined as any positive deflection of the recording pens of at least $1 \mathrm{~mm}$ within the CS.US interval. Amplitude of a UR on USa trials was defined as the point of highest deflection at least $300 \mathrm{msec}$ after CS onset. The position of the recording pens prior to the CS served as a baseline. Signal and gain settings were the same for all rabbits. It should be noted that the baseline for the NMR is very stable and spontaneous movement of the membrane or shifts in baseline are rare. The NM usually returns to its original baseline after each response. RESULTS AND DISCUSSION CR Frequency

The mean percentage of CRs for the experimental (E) and control (C) Ss conditioned at an III of $100 \mathrm{sec}$ are plotted against the right ordinate of Fig. 1 as a function of five daily blocks of 10 CS.US trials for 4 days of acquisition training. A similar graph for the experimental and control $\mathrm{S}$ s conditioned at an ITI of $200 \mathrm{sec}$ is presented in Fig. 2. Figure 1 shows that control Ss conditioned faster than the experimental $S s$ at the 100-sec ITI, but that no differences in rate of conditioning occurred at the 200-sec ITI. Though not statistically significant, the data in the 100-sec ITI group was for all practical purposes indistinguishable which employed twice as many Ss at this ITI.

Separate analyses of variance of $C R$ from the data of the Hupka et al study, frequency in eximction at each ITI revealed a marginally significant E-C by Day's by Blocks interaction. $F=2.22$ $\mathrm{df}=4 / 56 . p<.10$. indicating that control Ss tended to extinguish more slowly than experimental Ss. a finding consistent with the observation that experimental group conditioning was inferior to that of the control group. No such trend was apparent in the 200-sec ITI data.

\section{UR Amplitude}

Mean UR amplitude in millimeters for experimental and control Ss run at an ITI of $100 \mathrm{sec}$ are plotted against the left ordinate of Fig. 1 in five daily blocks of 10 reinforced trials during 4 days of acquisition training. A similar graph for the experimental and control $\mathrm{Ss}$ run at the 200-sec ITI is presented on the left ordinate of Fig. 2. As was previously reported by Hupka et al. and contrary to the findings with the human eyelid reflex. a comparison of $\mathrm{LR}$ amplitude (pooled over ITI levels) between paired CS-US and USa trials revealed smaller UR amplitudes during USa trials than during CS-US trials, $F=11.98, \quad \mathrm{df}=7 / 14 . \mathrm{p}<.001$. At the $100-\mathrm{sec}$ ITI a significant CS.US vs USa by Days interaction, $F=4.92, \quad \mathrm{df}=3 / 21$. $\mathrm{p}<.01$, indicated an increasing difference between the UR amplitude on CS-US trials and USa over conditioning sessions. In the 200-sec ITI group the difference between UR amplitude on CS-US and USa trials decreased over days, but this was not statistically significant. The UR amplitude on conditioning trials pooled over ITI levels was significantly larger for the control than for the experimental group, $F=6.56, \quad d f=1 / 28, \quad p<.025$. Separate analyses at each ITI level revealed a larger UR amplitude for the control Ss relative to the experimental $S s$ at the $100-\mathrm{sec}$ ITI. $\mathrm{F}=5.93, \mathrm{df}=1 / 14, \mathrm{p}<.05$, but not at the 200-sec ITI.

As in the Hupka et al study, a reliable amplitude difference (RAD) between UR amplitudes occurred prior to the first $C R$. A reliable amplitude difference in this study was defined as the first of three successive trials where the UR amplitude on conditioning trials exceeded the UR amplitude on USa trials. For the 200-sec ITI group the RAD was attained on the average by Trial 4 , while the first CR did not appear until Trial 49. In the $100-\mathrm{sec}$ ITI group the first RAD occurred on Trial 12, while the first CR occurred on Trial 69. This supports the conclusion that failure to observe diminution of the UR on CS-US trials is not merely a mechanical consequence of the $C R$ overcoming the recting inertia of the nictitating membrane

The principal findings of this study are: (1) Unpaired US presentations were detrimental to conditioning performance 
only if introduced within a comparatively short $(100 \mathrm{sec})$ ITI. (2) UR amplitude was smaller on unpaired trials than on paired trials.

One possible explanation for the occurrence of a conditioning decrement with a short but not a long ITI is the greater massing of US presentations, paired or unpaired, that results from either shortening the ITI or increasing the number of unpaired US presentations within a fixed ITl. Hupka et al (1970) compared conditioning of an experimental group (paired and unpaired US presentations) with a control group that had the same number and pattern of US occurrences as the experimental group but that always received the US paired with the CS. The latter group conditioned more rapidly than the experimental group, suggesting that it is the occurrence of the USa independent of any simple massed trials effect that interferes with conditioning. Putting it another way, it appears as if an unpaired US operates more as an "external inhibitor" than as a source of "reactive inhibition." Yet the timing of the USa in relation to a paired trial is a critical factor, and it is this observation that points to a consolidation hypothesis.

Consolidation theory assumes that the disrupting event acts retroactively by preventing "hardening" of the CS-CR connection. Yet it is also possible that the USa acts proactively by preventing the formation of the CS-CR connection. Although the proactive and retroactive influences of the USa cannot be separated in the present experiment, it seems clear that USa trials interfere basically with "associative" rather than "performance" processes. This conclusion is based on the fact that USa disruption does not persist beyond the labile. stage of conditioning. Once "consolidation" occurs, the USa loses its effect, with the result that experimental and control groups both achieve high asymptotic levels of responding.

\section{REFERENCES}

GORMEZANO, I. Classical conditioning. In J. B. Sidowski (Ed.), Experimental methods and instrumentation in psychology. New York: McGraw-Hill, 1966. Pp. 385-420.

HUPKA, R., KWATERSKI, S., \& YIOORE, J. W. Conditioned diminution of the ICR: Differences between the human eyeblink and the rabbit nictitating membrane response. Journal of Experimental Psychology, 1970. $83,45-51$.

KETTLEWELL, ‥ M.. \& PAPSDORF. J. D. The effects of an interpolated ITI stimulus on classical conditioning of the nictitating membrane response of the rabbit. Psychonomic Science. 1967. 9. 257.258.

KIVBLE. G. A. \& OST. J. W. A conditioned inhibitory process in eyelid conditioning. Journal of Experimental Psychology. 1961. $61,150-155$.
OST, J. W. Consolidation disruption and inhibition in classical conditioning. Psychological Bulletin, 1969, 72, 379*383.

PAPSDORF, J. D., \& KETTLEWELL, N. II. The effects of different interpolated IT stimulus-conditioned stimulus intervals on the acquisition of the classically conditioned nictitating membrane response of the rabbit. Psychonomic Science, 1968, 10, 171-172.
RESCORLA, R. A. Probability of shock in the presence and absence of CS in fear conditioning. Journal of Comparative \& Physiological Psychology, 1968, 66, 1-5.

STYDER, R. E.. \& PAPSDORF. J. D. The interaction of ITI interpolated stimuli and ISI on classical conditioning of the nictitating membrane response of the rabbit. Psychonomic Science, 1968, 12, 191-192.

\title{
Differences in reversal learning between two inbred mouse strains*
}

\author{
MERRILL F. ELIAS \\ Center for the Study of Aging and Human Development \\ Duke University Medical Center, Durham, N.C. 27706
}

$\mathrm{DBA} / 2 \mathrm{~J}$ and $\mathrm{C} 56 \mathrm{BL} / 6 \mathrm{~J}$ mice were given original learning and 11 reversals of a spatial discrimination habit. The former strain required fewer trials to shift from incorrect to correct responding after a reversal and made fewer errors on reversals. These data suggest that (1) genetic characteristics contribute to differences in reversal learning, and (2) generalizations concerning phyletic differences in reversal learning may be premature prior to testing of diverse strains within species.

Spatial reversal learning has been investigated for a wide range of species (Bitterman, 1965), but the house mouse has received relatively minor attention. This is unfortunate since strain comparisons within species have provided a useful paradigm for separating environmental and hereditary influences on learning capacity (Bovet, Bovet-Nitti, \& Oliverio, 1969). Elias $(1969,1970)$ and Meier \& Foshee (1963) have reported differences in reversal learning between mouse stocks and strains, but too few reversals were given to permit comparisons of reversal learning curves. The purpose of the present experiment was to give a sufficient number of reversals to two inbred mouse strains to allow for comparisons of learning curves. Inbred Strains DBA/2J (DBA) and C57BL/6J (C57) were of particular interest since Bovet et al (1969) have cited superior maze learning for the former as opposed to the latter strain as evidence for genetic influence on learning capacity.

\section{METHOD}

There were 12 8-week-old male Ss of

*This research was supported by a grant from the Linited Health Services of North Carolina and by Research Training Grant 5TOHD00164 from the National Institute of Child Health and Human Development each strain. A T-maze described by Waller, Waller, \& Brewster (1960) was used. It had rounded arms and no top or bottom, and was half immersed in a tank of water $\left(25 \pm 2^{\circ} \mathrm{C}\right)$. The front-back and top-bottom orientation of the maze in the water tank was reversed randomly between trials to control visual and olfactory cues. Ss swam from the start point at the stem end to a wire escape ladder at the end of the correct arm. The arms were curved so that the ladder could not be seen until a correct turn was made, and correction was permitted. For original learning (OL), the correct arm of the maze was defined for each $S$ as that chosen on less than half of the 20 habituation trials that preceded testing. For Reversal 1 (R-1), the direction of the correct response was opposite to OL. For Reversal 2 (R-2), the correct response was opposite to R-1, and so on until 11 reversals were completed. Ss were given two blocks of seven immediately successive trials each day, with $15 \mathrm{~min}$ between blocks. As soon as a criterion of 13 out of 14 consecutive correct responses was met on a single day, $\mathrm{S}$ was advanced to the next stage of learning, e.g., OL to R-1, or R-1 to R-2. Performance measures were: (1) mean errors prior to reaching criterion (errors to criterion), (2) number of trials required before $S$ shifted from incorrect to correct responding after a reversal (trials to 